\title{
Prolonged exposure to oil and gas flares ups the risks for hypertension
}

\author{
Egwurugwu, Jude Nnabuife ${ }^{1, ~}$, Nwafor, Arthur ${ }^{2}$ \\ ${ }^{1}$ Department of Human Physiology, College of Medicine and Health Sciences, Imo State University, Owerri, Nigeria \\ ${ }^{2}$ Department of Human Physiology, College of Health Sciences, University of Port Harcourt, Choba, Rivers State, Nigeria
}

Email address:

judenuel@gmail.com(Egwurugwu, J. N.)

\section{To cite this article:}

Egwurugwu, Jude Nnabuife, Nwafor, Arthur. Prolonged Exposure to Oil and Gas Flares Ups the Risks for Hypertension. American Journal of Health Research. Vol. 1, No. 3, 2013, pp. 65-72. doi: 10.11648/j.ajhr.20130103.15

\begin{abstract}
This study was done to assess the impacts of prolonged exposure to oil/gas flares on blood pressure measures in humans in the Niger Delta Region of Nigeria. The study was carried out among chronically exposed residents (475) and non-exposed individuals (315). All the subjects were matched for age, sex, occupation, education. Blood pressure was measured with manual mercury sphygmomanometer in sitting position after at least 10 minutes rest. The results showed that the test group subjects had statistically significant increase in systolic blood pressure(SBP), diastolic blood pressure(DBP) and mean arterial blood pressure(MAP) compared with the control $(\mathrm{p}<0.05)$. The males had higher prevalence of high blood pressure than the females $(\mathrm{p}<0.05)$. Results also showed that the blood pressure measures increased with age. In conclusion, prolonged exposure to oil/gas flares increased the incidence of hypertension and this may increase the risks for cardiovascular diseases.
\end{abstract}

Keywords: Gas Flare, Hypertension, Prolonged Exposure, Cardiovascular Disease

\section{Introduction}

Oil and gas exploration/exploitation is a product of man's quest for economic emancipation, wealth creation and job opportunities. Oil and gas exploration started in Nigeria in 1956 in the Niger Delta region of the country. Nigeria is the 6th largest producer of oil in the world and it is endowed with more gas reserves than oil [1-2]. The operations of the oil and gas industry include exploration, drilling, refining, distribution and marketing of the finished products to the consumers. During most of these activities, wastes are generated and discharged into the environment, either in solid, liquid or gaseous form [3]. Flared gas is one of such wastes generated in the oil and gas industry that should be turned into wealth creation and improving sustainable development but allowed to waste and pose health hazards. According to the World Bank-led GGFR (2013), every year, billions of Dollars worth of natural gas are wasted, burned or flared at oil fields across the world. Such flaring produces some 400 million tons of greenhouse emissions [4]

Gas flaring is one anthropogenic activity, defined as the "wasteful emission of greenhouse gases(GHGs) that causes global warming, disequilibrium of the earth, unpredictable weather changes and major natural disasters because it emits a cocktail of benzene and other toxic substances that are harmful to humans, animals, plants and the entire physical environment"[5]. It is a common practice of burning off unwanted, flammable gases via combustion in an open atmosphere, non - premixed flame[6]. According to a World Bank estimates in 2011[7], the annual volume of natural gas being flared and vented worldwide stood at about 140 billion cubic meters (bcm). Russia is the leading gas flaring country in the world, followed by Nigeria, Iran and Iraq.

During gas flaring, complete combustion though rarely achieved, releases relatively innocuous gases such as carbon dioxide and water, whereas incomplete combustion emits various compounds such as methane, propane, and hazardous air pollutants such as volatile organic compounds (VOCs), polycyclic aromatic hydrocarbons (PAHs) and soot[8]; benzene, naphthalene, styrene, acetylene, fluoranthene, anthracene pyrene, xylene and ethylene[9]. Flaring can also produce soot and other pollutant species that have negative effects on air quality and the environment [10-12]. 
Air pollution has been identified as one of the most critical environmental challenges confronting the Niger Delta region of Nigeria. The major air pollution sources in the region include traffic, industry and oil and gas flaring [13]. Of particular concern to the public is the involuntary subjection of the population 24hours/day; 7days/week to the chronic, low-level emissions of gas flaring base-stations, especially when they are insensitively sited near to homes, schools and hospitals[14]. There are more than 123 gas flaring sites in the Niger Delta, thus making Nigeria, the highest emitter of green house gases in Africa [15]. Chronic low-levels and prolonged exposure to these contaminants comes with a terrible cost to human health while his plants, animals, soil and water are not left out. Air pollutants have been linked with endothelial dysfunction and vasoconstriction, increased blood pressure (BP), prothrombotic and coagulant changes, systemic inflammatory and oxidative stress responses, autonomic imbalance and arrhythmias, and the progression of atherosclerosis [16-18].

Daily exposure to particulate matter has been related to acute increases in systemic arterial blood pressure [19-21].

Some constituents of oil and gas flare such as benzene [22-24], naphthalene and xylene [25], particulate matter, especially PM10 [26-27] can depress haemopoiesis. Crude oil is known to cause oxidative stress and increased membrane permeability in red cells [28].

Gas flare affects the sleep-wake cycle [3] and prolonged exposure to dioxins, especially 2, 3, 7, 8-tetrachlorodibenzodioxin (TCDD) can cause neurological symptoms such as sleep disturbance, headache and neuralgia[29]. Sleep deprivation is associated with high prevalence of hypertension[30-31]. Sleep deprivation causes significant increase in serum norepinephrine and sympathetic activity, venous endothelial dysfunction and hypertension[32]. Light pollution, excess exposure to artificial light, a common phenomenon in gas flared environment, is an emerging public health issue indirectly linked to cancer incidence[33] and many other adverse health effects such as environmental pollution[34] promoting circadian misalignment and physiological disturbances such as poor sleep quality and quantity, anxiety, depression, and modified feeding patterns[35].

To the best of our knowledge, no study has been done in the Niger Delta Region of Nigeria, assessing the possible effects of prolonged exposure to oil/gas flares on blood pressure measures on humans. Therefore, this study is our modest contribution in this regard.

\section{Materials and method}

\subsection{Research Design}

This is a case controlled study, comparing some residents, chronically exposed to low dose emissions of oil/gas flaring with non-exposed persons from another community.
Two different communities, with similar socioeconomic and cultural characteristic features, in the Imo East Senatorial zone, in the Niger Delta Region of Nigeria were chosen for the study. Egbema, an oil and gas producing community with active gas flaring by Shell Petroleum Development Company (SPDC) for more than 45 years, constitute the test group. This community is located in between many other active oil and gas flaring sites such as Ossu, Oguta and Izombe oil and gas fields operated by Addax and Akri and Ebocha oil and gas fields run by Nigeria Agip Oil Company. Thus, the residents are well exposed to the effects of oil and gas flaring. Alaoma Owerre - Ebeiri autonomous community, a non oil and gas producing area, constitute the control group population.

\subsection{Selection of Subjects}

Apparently healthy adults, between the ages of 18 to 80 years, who consented to in writing and/or thumb printed (after due explanation) to participate in the study, were randomly selected. All must have lived in their various communities consistently for more than 5 years. The research was approved by the Ethics Committee on Human Biomedical Research of the University of Port Harcourt, Nigeria and the study conforms to the Helsinki Declaration on Biomedical Research. Of the 3150 volunteers screened, 790 subjects (475 test groups and 315 control groups) met the inclusion criteria and therefore participated in the study. All known cases of hypertension, diabetes mellitus, metabolic syndrome, dyslipidemia, renal disease, atherosclerosis and contraceptive users were excluded from the study.

\subsection{Anthropometric Measures}

Age was measured in years. Weight was measured to the nearest $0.1 \mathrm{~kg}$ in light clothing while height was measured to the nearest centimeter without shoes. The subjects were weighed on a mechanical bathroom scale (Hanson, China) and their height measured with a wall-mounted ruler. The height measures were done by a research assistant with good vision and a height of $1.82 \mathrm{~m}$. Body mass index (BMI) was calculated by dividing weight $(\mathrm{kg})$ by height squared $\left(\mathrm{m}^{2}\right)\left(\mathrm{kg} / \mathrm{m}^{2}\right)$ using Quitelet's index.

\subsection{Blood Pressure Measurements}

Blood pressure was measured by a medical doctor with subjects in a sitting position and having rested for at least 10 minutes using a standard manual mercury sphygmomanometer and appropriate cuff sizes. Three separate readings were taken per subject, after two minutes intervals and the lowest readings recorded. Systolic blood pressure (SBP) and diastolic blood pressure (DBP) were taken at the $1^{\text {st }}$ and $5^{\text {th }}$ Korotkoff sounds respectively. Pulse pressure was calculated using SBP-DBP. Mean arterial blood pressure (MAP) using DBP plus one-third pulse pressure.

\subsection{Study Areas}




\subsection{Statistical Analysis}

Statistical Package for Social Sciences (SPSS) (version 17 for windows, SPSS Inc., Chicago, USA) was used to analyze the data. The differences in the various parameters studied between the test and control groups were evaluated using Kolmogorov - Simirnov Z statistic. Anova was used to assess differences within the groups. Statistically significant values were determined at $\mathrm{p}<0.05$ or $95 \%$ confidence level.

\section{Results}

790 subjects participated fully in the study and the results are presented in tables and figures.

Table 1. Anthropometrical data of the population.

\begin{tabular}{|c|c|c|c|c|}
\hline Parameter & $\begin{array}{l}\text { Control group } \\
(n=315)\end{array}$ & $\begin{array}{l}\text { Test group } \\
(n=475)\end{array}$ & P Value & Percentage difference \\
\hline Age(years) & $\begin{array}{l}40.62 \pm 0.96 \\
(18-93)\end{array}$ & $\begin{array}{l}44.12 \pm 0.86 \\
(18-103)\end{array}$ & $0.01^{\circ}$ & 7.88 \\
\hline Weight $(\mathrm{Kg})$ & $\begin{array}{l}66.37 \pm 0.65 \\
(40-111)\end{array}$ & $\begin{array}{l}55.40 \pm 0.53 \\
(35-120)\end{array}$ & $0.01^{\circ}$ & 17.95 \\
\hline Height(m) & $\begin{array}{l}1.56 \pm 0.00 \\
(1.50-1.78)\end{array}$ & $\begin{array}{l}1.57 \pm 0.00 \\
(1.50-1.80)\end{array}$ & $0.01^{\circ}$ & 0.64 \\
\hline Body mass index $\left(\mathrm{Kg} / \mathrm{m}^{2}\right)$ & $\begin{array}{l}27.26 \pm 0.26 \\
(17-43.7)\end{array}$ & $\begin{array}{l}22.31 \pm 0.19 \\
(15-44.9)\end{array}$ & $0.01^{\circ}$ & 19.97 \\
\hline
\end{tabular}

The control subjects had statistically significant increase in weight and body mass index compared with the test subjects $(\mathrm{p}<0.05)$ with percentage differences of 17.95 and $19.97 \%$ respectively (Table 1 ). The test subjects were taller than the control subjects $(\mathrm{p}<0.05)$.

Blood pressure measurements.

Table 2 compares the blood pressure measurements of the entire population. The blood pressure measurements (SBP, DBP and MAP) of the test subjects were significantly higher compared with the control $(\mathrm{p}<0.05)$. No statistically significant difference was noted in the PP of both groups ( $p>0.05$ ). The test group subjects recorded prevalence of $39 \%$ and $57 \%$ for systolic and diastolic hypertension compared with $28 \%$ and $35 \%$ for the control subjects.

Table 2. Blood pressure measurements of the population

\begin{tabular}{lllll}
\hline Parameter & Control group & Test group & P Value & Percentage difference \\
\hline $\mathrm{SBP}(\mathrm{mmHg})$ & $129.10 \pm 1.4$ & $134.1 .1 \pm 1.1$ & 0.01 & 3.85 \\
$\mathrm{SBP}<140 \mathrm{mmHg}$ & $226(72 \%)$ & $288(61 \%)$ & - & - \\
$\mathrm{SBP}>140 \mathrm{mmHg}$ & $89(28 \%)$ & $189(39 \%)$ & - & - \\
$\mathrm{DBP}(\mathrm{mmHg})$ & $82.97 \pm 0.70$ & $89.48 \pm 0.69$ & $0.01^{*}$ & 7.55 \\
$\mathrm{DBP}<90 \mathrm{mmHg}$ & $204(65 \%)$ & $205(43 \%)$ & - & - \\
$\mathrm{DBP}>90 \mathrm{mmHg}$ & $111(35 \%)$ & $270(57 \%)$ & - & - \\
$\mathrm{PP}(\mathrm{mmHg})$ & $45.98 \pm 0.89$ & $44.69 \pm 0.71$ & $0.45^{\circ}$ & 2.85 \\
$\mathrm{MAP}(\mathrm{mmHg})$ & $98.47 \pm 0.91$ & $104.37 \pm 0.77$ & $0.01^{*}$ & 5.82 \\
\hline
\end{tabular}

*Statistically significant difference.

$\mathrm{SBP}=$ Systolic blood pressure; $\mathrm{DBP}=$ Diastolic blood pressure

$\mathrm{PP}=$ Pulse pressure; $\mathrm{MAP}=$ Mean arterial pressure.

Table 3. Blood pressure measurements in males

\begin{tabular}{lllll}
\hline Parameter & Control group & Test group & P Value & Percentage difference \\
\hline $\mathrm{SBP}(\mathrm{mmHg})$ & $133.62 \pm 0.78$ & $139.54 \pm 0.2$ & 0.03 & $\mathbf{4 . 3 3}$ \\
$\mathrm{SBP}<140 \mathrm{mmHg}$ & $89(70 \%)$ & $72(51 \%)$ & - & - \\
$\mathrm{SBP}>140 \mathrm{mmHg}$ & $38(30 \%)$ & $68(49 \%)$ & 0.03 & - \\
$\mathrm{DBP}(\mathrm{mmHg})$ & $85.27 \pm 1.12$ & $92.58 \pm 1.18$ & - & $\mathbf{8 . 2 2}$ \\
$\mathrm{DBP}<90 \mathrm{mmHg}$ & $75(59 \%)$ & $43(31 \%)$ & - & - \\
$\mathrm{DBP}>90 \mathrm{mmHg}$ & $52(41 \%)$ & $97(69 \%)$ & 0.04 & $\mathbf{0 . 0 4}$ \\
$\mathrm{PP}(\mathrm{mmHg})$ & $51.85 \pm 1.71$ & $46.96 \pm 1.35$ & $\mathbf{9 . 9 0}$ \\
$\mathrm{MAP}(\mathrm{mmHg})$ & $105.65 \pm 1.60$ & $108.23 \pm 1.36$ & $\mathbf{2 . 4 1}$ \\
\hline
\end{tabular}

$\mathrm{SBP}=$ Systolic blood pressure; 
Table 4 compares the blood pressure measurements in the entire female population. There is statistically significant increase in SBP, DBP and MAP levels in the test group females compared with the control females with percentage differences of 4.56, 7.98 and $9.29 \%$ respectively. No significant differences in Pulse pressure $(\mathrm{p}>0.05)$ between the control and test subjects. The test group females had more persons with raised blood pressure compared with the control females.

Table 5 compares the various blood pressure measurements among the different age groups. There was a gradual increase in the blood pressure measures with increasing age especially in the test subjects compared with the control.

Table 4. Blood pressure measurements in the female population

\begin{tabular}{|c|c|c|c|c|}
\hline Parameter & Control group & Test group & P Value & Percentage difference \\
\hline $\mathrm{SBP}(\mathrm{mmHg})$ & $126.05 \pm 1.77$ & $131.93 \pm 1.30$ & 0.04 & 4.56 \\
\hline $\mathrm{SBP}<140 \mathrm{mmHg}$ & $137(73 \%)$ & $216(64 \%)$ & & \\
\hline $\mathrm{SBP}>140 \mathrm{mmHg}$ & $51(27 \%)$ & $119(36 \%)$ & & \\
\hline $\mathrm{DBP}(\mathrm{mmHg})$ & $81.41 \pm 0.88$ & $88.18 \pm 1.30$ & 0.04 & 7.98 \\
\hline $\mathrm{DBP}<90 \mathrm{mmHg}$ & $128(68 \%)$ & $162(48 \%)$ & - & - \\
\hline $\mathrm{DBP}>90 \mathrm{mmHg}$ & $60(32 \%)$ & $173(52 \%)$ & - & - \\
\hline $\mathrm{PP}(\mathrm{mmHg})$ & $42.02 \pm 0.85$ & $43.75 \pm 0.82$ & 0.10 & 4.03 \\
\hline MAP(mmHg) & $93.63 \pm 0.92$ & $102.76 \pm 0.93$ & 0.01 & 9.29 \\
\hline
\end{tabular}

$\mathrm{SBP}=$ Systolic blood pressure; $\mathrm{PP}=$ Pulse pressure;

$\mathrm{DBP}=$ Diastolic blood pressure

$\mathrm{MAP}=$ Mean arterial blood pressure.

Table 5. Blood pressure measurements by age groups.

\begin{tabular}{|c|c|c|c|c|}
\hline Parameter & Age group & Control & Test & $\%$ Difference \\
\hline \multirow{6}{*}{$\begin{array}{l}\text { Systolic blood pressure } \\
(\mathrm{mmHg})\end{array}$} & $<20$ & $144.35 \pm 5.79$ & $127.50 \pm 6.32$ & -11.67 \\
\hline & $20-29$ & $125.65 \pm 2.44$ & $133.67 \pm 3.34$ & 6.38 \\
\hline & $30-39$ & $129.80 \pm 3.03$ & $142.00 \pm 5.55$ & 9.39 \\
\hline & $40-49$ & $129.27 \pm 2.51$ & $138.57 \pm 4.04$ & 7.19 \\
\hline & $50-59$ & $133.64 \pm 2.96$ & $141.67 \pm 4.16$ & 6.00 \\
\hline & $>60$ & $134.62 \pm 3.58$ & $144.58 \pm 4.05$ & 7.39 \\
\hline \multirow{6}{*}{$\begin{array}{l}\text { Diastolic blood } \\
\text { pressure }(\mathrm{mmHg})\end{array}$} & $<20$ & $94.35 \pm 3.82$ & $85.00 \pm 8.66$ & -9.91 \\
\hline & $20-29$ & $84.59 \pm 1.33$ & $86.67 \pm 2.51$ & 2.46 \\
\hline & $30-39$ & $88.00 \pm 1.89$ & $88.50 \pm 2.74$ & 0.57 \\
\hline & $40-49$ & $86.15 \pm 1.55$ & $93.33 \pm 3.26$ & 8.33 \\
\hline & $50-59$ & $88.86 \pm 1.96$ & $98.75 \pm 2.84$ & 11.13 \\
\hline & $>60$ & $88.08 \pm 1.84$ & $97.83 \pm 2.53$ & 11.07 \\
\hline \multirow{6}{*}{ Pulse Pressure(mmHg) } & $<20$ & $50.00 \pm 4.12$ & $42.50 \pm 4.78$ & -15.00 \\
\hline & $20-29$ & $41.06 \pm 1.61$ & $47.00 \pm 2.26$ & 14.47 \\
\hline & $30-39$ & $41.80 \pm 2.01$ & $53.50 \pm 4.43$ & 27.99 \\
\hline & $40-49$ & $43.13 \pm 1.65$ & $45.24 \pm 2.14$ & 4.89 \\
\hline & $50-59$ & $44.77 \pm 2.14$ & $42.92 \pm 2.51$ & -4.13 \\
\hline & $>60$ & $46.54 \pm 2.33$ & $46.75 \pm 2.36$ & 0.45 \\
\hline \multirow{6}{*}{$\begin{array}{l}\text { Mean arterial blood } \\
\text { pressure }(\mathrm{mmHg})\end{array}$} & $<20$ & $111.01 \pm 4.14$ & $99.17 \pm 7.62$ & -10.66 \\
\hline & $20-29$ & $98.28 \pm 1.61$ & $102.33 \pm 2.60$ & 4.12 \\
\hline & $30-39$ & $101.93 \pm 2.13$ & $106.30 \pm 0.31$ & 4.29 \\
\hline & $40-49$ & $100.52 \pm 1.76$ & $108.41 \pm 3.39$ & 7.85 \\
\hline & $50-59$ & $103.78 \pm 2.11$ & $113.06 \pm 3.12$ & 8.94 \\
\hline & $>60$ & $103.59 \pm 2.31$ & $113.42 \pm 2.92$ & 9.48 \\
\hline
\end{tabular}




\section{Discussion}

\subsection{Anthropometric Data}

This study revealed that the weight and body mass index of the control subjects were higher than that of the test group population $(\mathrm{p}<0.05)$.. The result also showed that 46 per cent of the control subjects were over-weight while 22 per cent were obese, whereas 17 per cent of the test group were over-weight while 3 per cent were obese. Thus the ratio of obesity between the control and test population was about 7:1. The higher number of over-weight and obesity in the control subjects may among other reasons be due to nutritional transition i.e. a shift from a diet of simple, and sometimes, traditional foods with little variation to a diet more reliant on processed foods, animal-sourced foods, fats and sugars. The observed low prevalence of over-weight and obesity among the test group may be due to nutritional problems associated with oil and gas exploration/exploitation which can result from changes in land use (e.g. clearing/deforestation) or because of impacts on ecosystem that have implications for food security and diet [36] and increased farming and physical activities among the gas flared residents.

\subsection{Blood Pressure Measures}

The results showed that the systolic blood pressure (SBP),diastolic blood pressure(DBP) and mean arterial blood pressure( MAP) levels were statistically significantly increased in the test group subjects when compared with the control subjects $(\mathrm{p}<0.05)$. In the control group population, $28 \%$ had systolic blood pressure $\geq 140 \mathrm{mmHg}$ compared with $39 \%$ of the test group population. Also, $35 \%$ of the control subjects had diastolic blood pressure $\geq 90 \mathrm{mmHg}$ compared with $57 \%$ of the test population. The test population therefore, had greater number of hypertensives than the control subjects. Blood pressure(BP) is an established major risk factor for cardiovascular diseases[37-39]. Studies have demonstrated a correlation between environmental pollution and the development of cardiovascular disease (CVD) [40].

The high prevalence of hypertension among the gas flare exposed subjects may be due to:

Gas flaring affects sleep-wake cycle[41]. Sleep deprivation is associated with high prevalence of hypertension[30-31]. Sleep deprivation causes significant increase in serum norepinephrine and sympathetic activity, venous endothelial dysfunction and hypertension[32]. Paradoxical sleep deprivation reduced plasma angiotensin 11 concentrations, increased renal sympathetic nerve activity and possibly increase in blood pressure[41]. Modesti and co-workers[42] have demonstrated that for every hour of extra daylight experienced, the average nighttime systolic blood pressure rose by $0.63 \mathrm{mmHg}$.

Gas flaring causes increase in ambient temperature[43]. About 45.8 billion kilowatt of heat are discharged into the atmosphere of the Niger-Delta from 1.8 billion cubic feet of gas everyday[44]. Increase in ambient temperature can cause persistent and chronic dehydration among residents of gas flared environments. Dehydration causes reduced blood volume, increase in blood viscosity, and increase in blood pressure. Dehydration is further worsened by the poor water quality in the Niger Delta Region of Nigeria[45].

Exposure to ambient particulate matter with aerodynamic diameters $<10 \mu \mathrm{m}$ have positively been associated with blood pressure, and the underlying mechanism linking air pollution to increased cardiovascular risk may include disturbed circadian rhythms of renal sodium handling and blood pressure[46].

The Nigerian crude oil is known to contain heavy metals such as $\mathrm{Al}, \mathrm{Zn}, \mathrm{As}, \mathrm{Ba}, \mathrm{Fe}, \mathrm{Pb}, \mathrm{Co}, \mathrm{Cu}, \mathrm{Cr}, \mathrm{Mn}, \mathrm{Ga}, \mathrm{Sb}, \mathrm{Ni}$ and V[47]. Furthermore, surface and underground waters in gas flared environments tend to have more concentrations of heavy metals such as lead, barium, cadmium, selenium, manganese, magnesium and copper than non - gas flared area[45,47]. The residents of the Niger Delta Region are therefore exposed not only to the various air and soil pollutants but also to water contaminants especially the heavy metals. And some heavy metals such as lead, arsenic, barium and cadmium, present in oil and gas flares, can also cause raised blood pressure[49-52].

Hypertension can also increase serum uric acid (SUA) via elevated serum lactate levels. Hypertension initially produces renal microvascular diseases and local tissue hypoxia, as evidenced by increase in serum lactate. The lactate decreases tubular secretion of uric acid, leading to increased serum levels. Intra-renal ischaemia can also contribute to generation of uric acid via xanthine oxidase. It is also possible that metabolic alterations or disturbances (hyperinsulinemia) or sympathetic activity may produce changes in renal sodium handling, leading to increased arterial pressure, decreased renal blood flow and decreased uric acid secretion. This, in turn, increases purine oxidation resulting in increased production of reactive oxygen species(ROS), subsequent vascular injury, and reduced nitric oxide[53-55]. The increase in hypertension amongst the exposed individuals may also be due to the effects of oil and gas flares on the kidney. Chronic dehydration associated with prolonged exposure to oil and gas flares can affect the kidneys. Elevated urea can arise due to persistent dehydration and reduced renal perfusion[56].Hypertension is both an important cause and consequence of chronic kidney disease[57]. Chronic kidney disease is the most common form of secondary hypertension and its also an independent risk factor for cardiovascular morbidity and mortality[58-59].

Furthermore, gas flaring is associated with noise pollution not only from the blazing fire but also from vehicular and human traffic as well as from movement of heavy duty machineries. Noise pollution contributes not only to cardiovascular disease, but also to hearing loss, sleep disruption, social handicaps, diminished productivity, 
impaired teaching and learning, absenteeism, increased drug use, and accidents[60]. Noise sensitivity is associated with hypertension and increased coronary heart and cardiovascular mortality[61].

\subsection{Hypertension and Gender Differences}

This study also showed that the prevalence of all the blood pressure measures ( SBP, DBP, PP and MAP) were higher in males than females. The increase in blood pressure measures in the males compared with the females were statistically significant $(p<0.05)$ among the control and test subjects. The increase in blood pressure measures in males may be attributable to the influence of the constituents of the gas and oil flares being more in males than females.

Men tend to have higher blood pressure than women through much of life irrespective of race, culture and ethnicity[62-65]. . It has also been observed in other species such as dogs, rats, mice and chickens and it is found also in induced, genetic and transgenic animal models of hypertension[62, 64,66]. Men with hypertension were less likely than women to be aware of their condition and to be currently taking their antihypertensive medication[67].

\subsection{Blood Pressure and Age Classification}

The results showed that systolic blood pressure, diastolic blood pressure and mean arterial blood pressure increased with increasing age. The increase in hypertension may have resulted from the many varied factors associated with prolonged involuntary exposure to gas flares such as increased thermal temperature, chronic and persistent dehydration, particulate matter, dyslipidemia and renal pathology. Increase in hypertension with age among the residents could be associated with increases in exposure level and duration. However, in the general population, the prevalence of hypertension increases with age[67].

\section{References}

[1] N. Aston-Jones, 1998. The Human Ecosystem of the Niger Delta: An Era Handbook, Environmental Rights Action, Lagos, Nigeria. Pp 136-138.

[2] NNPC (Nigerian National Petroleum Corporation). 2011 Draft Annual Statistical Bulletin. www.nnpcgroup.com. [Accessed on August 12, 2012]

[3] A.E.Gobo, G. Richard, and I.U.Ubong, 2009. Health Impact of Gas Flares on Igwuruta/Umuechem Communities in Rivers State. Journal of Applied Science and Environmental Management, vol.13(3): 27-33.

[4] World Bank (2012): World Bank sees warning sign in gas flaring Increase.Press Release No. 2013/005/SDN, Geneva. [Accessed: July 3, 2012].

[5] World Bank (1995). Defining and Environmental Strategy for the Niger Delta. West Central Africa Department, World
Bank, Washington DC, P 150.

[6] J.D.M McEwen and M.R. Johnson, 2010. Black carbon particulate matter emission factors for buoyancy driven associated gas flares. Journal of Air Waste Management Association, 62(3): 307-321.

[7] World Health Organization(WHO) (2011): Burden of disease from environmental noise. Quantification of healthy life years lost in Europe. Geneva.

[8] W.D. Kindzierski, 2000. Importance of Human environmental exposure to Hazardous air pollutants from Gas flares. Environmental Review, vol. 8:41-62.

[9] M.T.Strosher, 1996. Investigation of Flare Gas Emissions in Alberta; Calgary,Alberta.

[10] M.T. Strosher, 2000. Characterization of emissions from diffusion flare systems. Journal of Air Waste Management Association, vol. 50(10): 1723-1733.

[11] M.R. Johnson and L.W. Kostiuk, 2000. Efficiencies of lowmomentum jet diffusion flames in crosswinds. Combustion and Flame, vol.123: 189-200.

[12] M.R. Johnson, D.J. Wilson, and L.W. Kostiuk, 2001. A fuel stripping mechanism for wake-stabilized jet diffusion flames in crossflow. Combustion Science and Technology, vol.169:155-174.

[13] G.C. Ana, 2011. Air Pollution in the Niger Delta Area: Scope, Challenges and Remedies, The Impact of Air Pollution on Health, Economy, Environment and Agricultural Sources, Dr. Mohamed Khallaf (Ed.),ISBN: 978-953-307-528-0, InTech, Available from: http://www.intechopen.com/books/the-impact-ofairpollution-on-health-economy-environment-andagricultural-sources/air-pollution-in-the-niger-delta-areascopechallenges-and-remedies. [Accessed on January 23, 2013].

[14] A. Nwafor, 2013. Life under assault: no where to hide. University of Port Harcourt Inaugral Lecture Series No 102.

[15] E. Uyigue and M. Agho, 2007. Coping with Climate Change and Environmental Degradation in the Niger-Delta of South Nigeria. Benin. Community Research andDevelopment Centre (CREDC).

[16] C.A. Pope and D.W Dockery, 2006. Health effects of fine particulate air pollution: lines that connect. Journal of Air Waste Management Association, vol. 56: 709-742.

[17] R.D. Brook, 2008. Cardiovascular effects of air pollution. Clinical Science (London), vol. 115: 175-187.

[18] B.Z. Simkhovich, M.T. Kleinman and R.A. Kloner, 2008. Air pollution and cardiovascular injury epidemiology, toxicology, and mechanisms. Journal of American College of Cardiology, 52: 719-726.

[19] K.J. Chuang, C.C. Chan, G.M. Shiao and T.C. Su, 2005. Associations between submicrometer particles exposures and blood pressure and heart rate in patients with lung function impairments. Journal of Occupation and Environmental Medicine, vol. 47: 1093-1098.

[20] J.H. Choi, Q.S. Xu, S.Y. Park, J.H. Kim, S.S. Hwang, K.H. Lee, H.J.Lee and Y.C. Hong, 2007. Seasonal variation of effect of air pollution on blood pressure. Journal of 
Epidemiology and Community Health, vol.. 61: 314-318.

[21] A.H. Auchincloss, A.V. Diez Roux, J.T. Dvonch, P.L. Brown, R.G. Barr, M.L. Daviglus, D.C. Goff, J.D. Kaufman and M.S. O'Neill, 2008. Associations between recent exposure to ambient fine particulate matter and blood pressure in the Multi-ethnic Study of Atherosclerosis (MESA). Environmental Health Perspective, vol. 116: 486-491.

[22] Agency for Toxic Substances and Disease Registry (ATSDR) (2007): Toxicological Profile for Benzene (update). US Department of Health and Human Services, Atlanta, Georgia. 200-2004-09793,1-415.

[23] IRIS. (2007). Benzene. Integrated Risk Information System. Washington, DC: U.S. Environmental Protection Agency. http://www.epa.gov/iris/subst/index.html. May 1, 2007

[24] O.M. Adiembo and A. Nwafor, 2010. Effect of Prolonged Exposure to Gas Flaring on Some Haematological Parameters of Humans in the Niger Delta Region of Nigeria. Journal of Applied Science and Environmental Management,vol.14(1): 13-15.

[25] J. Argo, 2002. Unhealthy effects of upstream oil and gas flaring ( US-SIC $=1311$ and US SIC 1389). A Report prepared for Save Our Seas and Shores(SOSS) for presentation before the Public Review Commission into Effects of Potential Oil and Gas Exploration, Drilling Activities within Licences 2364, 2365 and 2368, Sydney NS.

[26] P.K. Padhy and B.K. Padhi, 2009. Effects of biomass combustion smoke on haematological and antioxidant profile among children(8-13 years) in India. Inhalation Toxicology, 21:705-11.

[27] P. Poursafa, R. Kelishadi, A. Amini, A. Amini, M.M. Amin, M. Lahijanzadeh and M. Modaresi, 2011. Association of air pollution and hematologic parameters in children and adolescents. Jornal de Pediatria (Rio J), vol. 87(4):350-6.

[28] D.U.Owu, U.B. Udoete, N. Azah, and E.U. Eyong, 2005. Effects of Bony Light crude oil on some haemtological parameters of Guinea pigs. Biokemistri, Vol.17 (2): 165-170.

[29] M. Neuberger, M. Kundio and R. Jager, 1998. Chloracne and morbidity after dioxin exposure (preliminary results). Toxicology Letters, vol. 96-97:347-50.

[30] J.M. Legramante and A. Galante, 2005. Sleep and hypertension: a challenge for the autonomic regulation of the cardiovascular system. Circulation, vol.112:786-788.

[31] D.J.Gottlieb, S. Redline, F.J. Nieto, C.M. Baldwin, A.B. Newman, H.E. Resnick and N.M. Punjabi, 2006. Association of usual sleep duration with hypertension: the Sleep Heart Health Study. Sleep, vol.29(8): 1009-14.

[32] J.L. Dettoni, F.M. Consolim-Colombo, L.F. Drager, M.C. Rubira, S.B.P. Cavasin de Souza, M.C. Irigoyen, C. Morstarda, S. Borile, E.M. Krieger, H. Moreno and G. Lorenzi-Filho, 2012. Cardiovascular effects of partial sleep deprivation in healthy volunteers. Journal of Applied Physiology, vol. 113 (2): 232-6.

[33] R. Witter, K. Stinson, H. Sacket, S. Putter, G. Kinney, D. Teitelbaun and L. Newman, 2008. Potential exposurerelated human health effects of oil and gas development: a literature review (2003-2008). www.ccag.org.au/images/stories/pdfs/literaturereviewwitter et al2008.pdf. [accessed 04/01/13.]
[34] R. Chepesiuk, 2009. Missing the Dark: Health Effects of Light Pollution Environmental Health Perspective, vol. 117(1): A20-A27.

[35] C. Escobar, R. Salgado-Delgado, E. Gonzalez-Guerra, A.T. Osorio, M. Angeles-Castellanos and M. Ruud, R.M. Buijs, 2011. Circadian Disruption Leads to Loss of Homeostasis and Disease. Sleep Disorder. 2011: 964510.

[36] World Health Organization (WHO) (2010): Workshop on managing the health impacts of oil and gas and mining projects. Second Inter-ministerial conference on health and environment in Africa, Luanda, Angola, 23-26 Nov. 2010.

[37] S. Mac Mathon, R. Peto, J. Cutler, P. Sorlie, J. Neaton, R. Abbott, J. Godwin, A. Dyer and J. Stamler, 1990. Blood pressure, stroke, and coronary heart disease, part 1: prolonged differences in blood pressure: prospective observational studies corrected for the regression dilution bias. Lancet, 355:765-774

[38] J. Stamler, R. Stamler and J.D. Neaton, 1993. Blood pressure, systolic and diastolic, and cardiovascular risks: US population data. Archives of Internal Medicine, 153:598-625.

[39] P.K. Whelton, 1994. Epidemiology of hypertension. Lancet, 344:101-106.

[40] P. Jennrich, 2013. The influence of arsenic, lead, and mercury on the development of cardiovascular diseases. ISRN Hypertension, ID234034.

[41] J.C. Perry, C.T. Bergamaschi, R.R. Campos, M.L. Andersen, N. Montano, D.E. Casarini and S. Tufik, 2011. Sympathetic and angiotensinergic responses mediated by paradoxical sleep loss in rats. Journal of Renin-Angiotensin-Aldosterone System. DOI: 10.1177/1470320310391504

[42] P.A. Modesti, M. Morabito, L. Massetti, S. Rapi, S. Orlandini, G. Mancia, G.F. Gensini and G. Parati, 2013. Seasonal blood pressure changes: an independent relationship with temperature and daylight hours. Hypertension, vol. 61(4):908-14.

[43] O.J. Oseji, 2011. Environmental impact of gas flaring within Umutu-Ebedei gas plant in Delta State, Nigeria. Archives of Applied .Science Research, vol. 3 (6):272-279.

[44] K.K. Aaron, 2006. Human Rights Violation and Environmental Degradation in the Niger-Delta, In Elizabeth Porter and Baden Offord(eds), Activating Huma Rights, Oxford, Barne, New York.

[45] J.N. Egwurugwu, A. Nwafor, P. Nwankpa, O.J. Olorufemi and J.E. Okwara, 2013. Prolonged gas flaring and water quality in Obiakpu, Egbema Imo State Nigeria. International Research Journal Environmental Science, 2(4):1-5.

[46] D. Tsai, M. Riediker, G. Wuerzner, M. Maillard, P. MarquesVidal, F. Paccaud, P. Vollenweider, M. Burnier and M. Bochud, 2012. Short-term Increase in Particulate Matter Blunts Nocturnal Blood Pressure Dipping and Daytime Urinary Sodium Excretion. Hypertension, vol. 60:10611069.

[47] G. Idodo-Umeh and A.E. Ogbeibu, 2010. Bioaccumulation of the Heavy Metals in Cassava Tubers and Plantain Fruits Grown in Soils Impacted with Petroleum and NonPetroleum Activities. Research Journal of Environmental Sciences, vol.4: 33-41. 
[48] C.N. Nwankwo and D.O. Ogagarue, 2011: Effects of gas flaring on surface and ground waters in Delta State Nigeria. Journal of Geology and Mining Research, vol.3(5): 131-136.

[49] M. Rahman, M.Tondel, S.A. Ahmad, I.A. Chowdhury, M.H Faruquee and O.O. Axelson, 1999. Hypertension and arsenic exposure in Bangladesh. Hypertension, vol. 33:7478.

[50] S. Marcus, 2001. Toxicity of Lead. Wassan WI Medical Library Thomson, pp. 76-77.

[51] S. Satarug, M. Nisho, J.M.Lasker, R.J. Edwards and M.R. Moore, M.R. 2006. Kidney dysfunction and hypertension: Role for Cadmium, P450 and Heme Oxygenases. Tohoku Journal of Experimental Medicine, vol. 208: 179-202.

[52] S. Satarug, H. Scott, G.M.A. Sens and D.A. Sens, 2010. Cadmium, Environmental Exposure, and Health Outcomes. Environmental Health Perspective, vol. 118(2): 182-190.

[53] M.H. Alderman, H. Cohen and S. Madhavan, 1998. Distribution and determinants of cardiovascular events during 20 years of successful antihypertensive treatment. Journal of Hypertension, vol.,16:761-9.

[54] H.J.Ward, 1998. Uric acid as an independent risk factor in the treatment of hypertension. Lancet, 352:670-1.

[55] C. Bickel, H.J. Rupprecht, S. Blankenberg, G. Rippin, G. Hatner, A. Daunhauer, et al., 2002. Serum uric acid as an independent predictor of mortality in patients with angiographyically proven coronary artery disease. Am.J.Cardiol, 89: 12-7.

[56] M.H. Rosner, and W.K. Bolton, 2006. Renal function testing. American Journal of Kidney Diseases, vol.47(1):174-183.

[57] F.M Tedla, A. Brar, R. Browne and C. Brown, 2011. Hypertension in chronic disease: Navigating the Evidence. International Journal of Hypertension, vol.2011. Article ID 132405,9 pages. Doi:10,4061/2011/132405.
[58] N. S. Anavekar, J.J.V. Mc Murray, E.J. Velazquez, et al., 2004. Relation between renal dysfunction and cardiovascular outcomes after myocardial infacrction. New England Journal of Medicine, vol.351(13):1285-1295.

[59] A.S. Go, G.M. Chertow, D. Fan, McCulloch and C.Y.Hsu, 2004. Chronic kidney disease and risks of death, cardiovascular events, and hospitalization. New England Journal of Medicine, vol. 351(13):1296-1305.

[60] L. Goines and L. Hagler, 2007. Noise pollution: a modern plaque. Southern Medical Journal. 100(3):287-294.

[61] M. Heinonen-Guzejev, H.S. Vuorinen, H. MussaloRauhamaa, K. Heikkila, M. Koskenvuo and J. Kapiro, 2007. The association of noise sensitivity with coronary heart and cardiovascular mortality among Finnish adults. Science of Total Environment, 372:406-412.

[62] J. F. Reckelhoff, 2001. Gender differences in the regulation of blood pressure. Hypertension, vol. 37: 1199-1208.

[63] C. Maric, 2005. Sex differences in cardiovascular disease and hypertension: involvement of the Renin-Angiotensin System. Hypertension, vol. 46: 475-576.

[64] K. Sandberg and H. Ji, 2012. Sex differences in primary hypertension. Biology of Sex Differences, vol. 3:7.

[65] H. Shin, M. Shin and J. Rhee, 2012. Gender differences in the association between self-rated health and hypertension in a Korean adult population. BMC Public Health, vol. 12:135.

[66] J.F. Reckelhoff, H. Zhang, K. Srivastava and J.P. Granger, 1999. Gender differences in hypertension in spontaneously hypertensive rats: role of androgens and androgen receptor. Hypertension, vol. 34: 920-9.

[67] S.S. Yoon, V. Burt, T. Louis, M.D. Carroll, 2012. Hypertension among adults in the United States, 2009-2010. NCHS data brief, no 107. Hyattsville, MD:National Center for Health Statistics. 